\title{
A PRECARIZAÇÃO ESTRUTURAL DO TRABALHO NA CIVILIZAÇÃO DO CAPITAL EM CRISE: o precariado como enigma contemporâneo
}

\author{
Alba Maria Pinho de Carvalho \\ Universidade Federal do Ceará (UFCE)
}

\begin{abstract}
A PRECARIZAÇÃO ESTRUTURAL DO TRABALHO NA CIVILIZAÇÃO DO CAPITAL EM CRISE: o precariado como enigma contemporâneo

Resumo: No contexto da civilização contemporânea do capital, este artigo enfoca a precarização estrutural do trabalho, a expressar uma nova morfologia laboral, na temporalidade histórica da crise estrutural do capital. Salienta a nova forma de precarização ampliada do trabalho, nos marcos da "maquinofatura", a perpassar experiências de diferentes segmentos de trabalhadores e trabalhadoras, encarnando o estranhamento do "homem-que-trabalha" a manifestar-se na totalidade da sua vida e na cotidianeidade. Demarca a universalidade da condição de proletariedade, como condição existencial de homens e mulheres que vivem sob a ordem burguesa, em tempos de capitalismo global. Analisa a emergência e constituição do precariado como uma camada social da classe trabalhadora que, nesta segunda década do século XXI, se amplia e ganha visibilidade nos países capitalistas considerados centrais. Delineia vias analíticas distintas na busca de explicação do precariado no interior da nova temporalidade histórica do sistema do capital, em meio às suas contradições. Configura esta camada precarizada de trabalhadores na articulação entre faixa geracional, grau educacional e forma de inserção no trabalho e no mundo social, questionando a força emancipatória das lutas desse precariado. Sustenta, como via de estudo, que o precariado está a afirmar-se no cenário brasileiro, constituindo a base social dos movimentos sociais que irromperam, na vida brasileira, em junho e julho de 2013. Por fim, afirma ser o precariado um enigma contemporâneo, a ser desvendado pelo pensamento crítico e radical neste século XXI.

Palavras-chave: Crise do Capital, condição de proletariedade, precarização estrutural do trabalho, precariado.
\end{abstract}

THE STRUCTURAL PRECARIOUSNESS OF WORK IN THE CIVILIZATION OF THE CAPITAL IN CRISIS: the precariat as a contemporaneous enigma

Abstract: Within the context of the current civilization of capital, this article approaches the structural precariousness of labor, that tends to express a new work morphology, in the historical timeline of the capital crisis It highlights the new enlarged form of labor precariousness, within the limits of the "machine-facture process", that brings forth experiences from different segments of workers giving shape to the estrangement of the "man-who-works" that is seen along his daily life. It demarcates the universality condition of the proletariat, as an existence-related situation of men and women who live under the bourgeoisie, at a time of global capitalism. It analyses the surge and constitution of precariousness as a social stratum from the working class that is gaining space and visibility in major capitalist countries in this second decade of the twenty-first century. It delineates distinct analytic lines in search of explaining precariousness according to the new historical timeline of capital, amid its contradictions. It configures this precariousness-dominated stratum of workers in the articulation of factors such as age, education and insertion in the work force and the social world, questioning the fighting emancipation force of it. It sustains, as a mean of study, that the proletariat is establishing itself within the Brazilian scenario, shaping up the social basis of social movements that made their way to the Brazilian life in June and July of 2013. Finally, it affirms that precariousness of labor is a contemporaneous enigma to be solved by the critical and radical thinking within the current century.

Keywords: Capital crisis, proletariat condition, structural precariousness of labor, labor precariousness. 
1 À GUIZA DE INTRODUÇÃO: o sistema do capital no século $X X \mid$

Nos circuitos da História, no final do século XX, e limiar do século XXI, o sistema do capital está a vivenciar um processo de aceleradas mutações, vinculadas a um desenvolvimento da ciência e da tecnologia sem limites e sem controles, apartado das necessidades humanas e desconectado da ética da sustentabilidade e do cuidado. A revolução da informática e da comunicação, combinada com a tendência do capitalismo para ampliar a lei do valor a mais e mais dimensões da vida social, transformam o modo de produção e o modo de vida. É a civilização contemporânea do capital ${ }^{1}$, a encarnar a sua nova temporalidade histórica, no âmbito de uma dupla demarcação: novo momento no desenvolvimento do capitalismo, nos marcos da mundialização com dominância financeira; momento histórico de explicitação da crise estrutural do capital ${ }^{2}$. São tempos de mudanças e redefinições que interpelam o pensamento crítico, circunscrevendo um desafio do presente. É a História a exigir o trabalho de reflexão teórica, mobilizando a imaginação dialética, no desvendamento crítico das novas condições de expansão ilimitada do capital, em novas conexões de tempo e espaço. Eis uma tarefa epistemológicopolítica do século XXI, a impor uma agenda de estudos e discussões.

Nas últimas quatro décadas, no contexto de tecnologização da ciência, sob a égide das forças cibernético-informacionais, o sistema do capital vem efetivando transformações no seu padrão de acumulação e nos seus mecanismos de valorização, passando a encarnar novas formas de dominação social, a assumirem configurações peculiares: são formas de dominação abstratas, impessoais, sutis, indefinidas, polifacetadas e profundamente penetrantes, a perpassarem a economia, a política, a cultura, redefinindo subjetividades (CARVALHO, 2012b). É inconteste o poderio do dinheiro neste momento contemporâneo, a consubstanciar a lógica que preside o sistema do capital em tempos de mundialização, permeando a totalidade das relações sociais:

\footnotetext{
Produz-se por dinheiro, especula-se por dinheiro, mata-se por dinheiro, corrompe-se por dinheiro, organiza-se toda a vida social por dinheiro, só se pensa em dinheiro. Cultua-se o dinheiro, o verdadeiro deus da nossa época - um deus indiferente aos homens, inimigo da arte, da cultura, da solidariedade, da ética, da vida do espírito, do amor. Um deus que se tornou imensamente mediocrizante e destrutivo. E que é insaciável: a acumulação de riqueza abstrata é, por definição, um processo sem limites. (BENJAMIN, 2004, p. 2).
}

De fato, é uma temporalidade histórica, marcada pela exacerbação da liquidez, da instabilidade e da insegurança, a explicitar-se, no cenário mundial de 2008, na crise do capital.

A rigor, esta crise, que marca o tempo presente, é grave e profunda, constituindo uma crise estrutural, com raízes fincadas nos novos padrões de acumulação e valorização do capital ${ }^{3}$. É uma crise com permanentes desdobramentos e deslocamentos que, por sua própria natureza, obrigatoriamente, afeta a humanidade como um todo (MÉSZÁROS, 2009; 2013). Eclodiu com intensidade dramática nos países capitalistas mais poderosos do mundo, que se autodenominam capitalistas avançados. Estados Unidos, potência imperial, motor do mundo onde a crise emergiu, constituiu-se e difundiu-se e que, hoje, com seu catastrófico endividamento externo de 17 trilhões de dólares, encarna grave ameaça de uma colossal quebra, equivalente à magnitude de um terremoto econômico para o mundo todo. A Europa desmonta-se em sua aparente e tradicional solidez e estremece mergulhada em crise sem precedentes e a austeridade passa a ser um modo de vida imposto a populações de determinadas nações europeias.

$E$ a crise, nos seus permanentes deslocamentos e distintos ritmos, chega aos países da América Latina, com o esgotamento do ciclo de crescimento, nos marcos de uma acumulação rentista extrativista, decorrente de fatores que se conjugaram no final da primeira década do século XXI e limiar da segunda: entrada do capital financeiro que, no contexto da crise nos países capitalistas considerados avançados, deslocamse para as regiões nomeadas de periféricas; relações comerciais com a China, a afirmar-se como uma potência exportadora e importadora, com extraordinária demanda por produtos primários agrícolas e minerais (CARVALHO, 2013). E, especificamente no Brasil, as expressões da crise do capital ganham visibilidade em 2013, evidenciando a instabilidade e o risco dos arranjos do modelo brasileiro, nos circuitos híbridos do ajuste e do neodesenvolvimentismo (CARVALHO; CASTRO, 2013).

Nenhum país pode evocar imunidade a esta crise estrutural do capital, nem mesmo a China, com seu superávit de trilhões de dólares que, neste capitalismo de liquidez e risco, pode evaporar-se de um dia para outro, em meio a uma turbulência (MÉSZÁROS, 2013).

Em verdade, o sistema do capital, no século $X X I$, confronta-se com uma crise civilizacional, expressando a insustentabilidade do seu modo de funcionamento, fundado na sua expansão predatória e sem limites, a manifestar-se numa articulação de crises: ambiental, climática, alimentar, energética, financeira, crise do mundo do trabalho, crise social e uma profunda crise de sentidos. E, múltiplos são os fenômenos indicadores desta crise civilizatória: uso intensivo e indiscriminado de recursos naturais, 
beirando ao débâcle; a privatização exacerbada de bens comuns: a água, o ar, a biodiversidade; a expulsão do próprio processo de trabalho de centenas de milhões de trabalhadores/trabalhadoras que se tornam supérfluos ao modo de funcionamento do capital; precarização estrutural do trabalho; universalização da condição de proletariedade e precarização existencial; violências e inseguranças sempre em aprofundamento; exclusões sociais e apartações; consumismo ilimitado como modo de existência social; a lógica da descartabilidade a perpassar a totalidade das relações sociais.

Nesse contexto de transformações, crises e riscos constituem o mundo social dominado pela expansão da lógica do capital, em detrimento da lógica das necessidades humanas.Arigor, estalógica de expansão do capital não tem limites e controles e, precisamente, nesse momento contemporâneo do capitalismo, acentua e agrava a sua tendência destrutiva, não poupando nada, nem ninguém, a minar as condições fundamentais de sobrevivência humana e a colocar em risco o planeta Terra. Neste sentido, István Mészáros (2013, p. 6) alerta para a gravidade dos problemas atuais do capitalismo no contexto da crise estrutural do capital, a afetar até a "[...] dimensão mais fundamental do controle social metabólico da humanidade, incluindo a natureza de forma perigosa." E, contrapondo-se à Schumpeter e sua tese da destruição criativa, afirma estar acontecendo no sistema do capital, nesta nova temporalidade histórica, uma produção destrutiva.

O sistema parece atingir o limite de suas contradições, colocando em questão o futuro do próprio capitalismo e seus permanentes deslocamentos. Como bem sinaliza David Harvey (2011), em tempos de crise, torna-se evidente a própria irracionalidade do capitalismo. Assim, Mészáros (2013), atualizando a alternativa histórica, circunscrita por Rosa de Luxemburgo - Socialismo ou Barbárie - afirma: Barbárie, se tivermos sorte. E argumenta que "[...] a exterminação da humanidade é a ameaça que se desenrola." (MESZÁROS, 2013, p. 11). Slavoj Zizek (2012) sustenta que o capitalismo se aproxima rapidamente da sua crise final e que, assim, estamos vivendo no fim dos tempos, indicando como quatro cavaleiros do apocalipse: a crise ecológica; as consequências da revolução biogenética; os desequilíbrios do próprio sistema (problemas de propriedade intelectual, a luta vindoura por matéria-prima, comida e água) e o crescimento explosivo de divisões e exclusões sociais. David Harvey (2011), reconhecendo ser esta uma crise estrutural, afirma não se tratar de uma crise terminal, argumentando que o sistema do capital tem novos deslocamentos e que as crises são momentos de paradoxos e possibilidades e, desse modo, diferentes alternativas podem surgir. Abre-se, assim, um campo de polêmicas sobre o futuro do sistema do capital como contradição em processo. enigma contemporâneo

Esta crise contemporânea do capital, como crise estrutural de valorização, ganha visibilidade nas configurações contemporâneas do mundo do trabalho, gestando a nova precariedade estrutural do trabalho, como dimensão constitutiva do sistema do capital, nesta sua temporalidade histórica no século XXI. É o "[...] novo (e precário) mundo do trabalho no século XXI." a exigir um sistema categorial novo (ALVES, 2013) ${ }^{4}$. De fato é a exigência da ampliação conceitual e de alargamento analítico no campo do marxismo que sustenta Carlos Nelson Coutinho (1994), buscando apropriar-se, no âmbito pensamento crítico, das novas determinações e mediações nos circuitos dos movimentos da História.

Este novo momento do capitalismo, do final do século XX e limiar dos anos 2000, nos marcos da expansão ilimitada e destrutiva do capital, sustentase em uma mistificação ideológica que conduz ao extremo individualismo e ao imobilismo, operantes na vida social. A rigor, a própria lógica que preside o desenvolvimento capitalista, qual seja, a lógica da concorrência do mercado, do produtivismo impõe-se, cada vez mais, como ideologia dominante (HARVEY, 2011). É o predomínio de uma cultura do mercado, da produtividade e da descartabilidade. Assim, materializando a dinâmica expansionista ilimitada do mercado, institui-se a cultura do descartável, a espraiar-se na vida social, reconfigurando as formas de sociabilidades contemporâneas: descartabilidade de objetos, de relações, de pessoas e, especificamente, de homens e mulheres trabalhadores(as).

Nos circuitos da crise estrutural, os governos dos Estados Unidos da Europa e de outras partes do mundo parecem redescobrir o estatismo todo privatizado (ANTUNES, 2009), fazendo ressurgir o que se pode denominar de neokeynesianismo, a partir da legitimação do intervencionismo estatal como caminho de salvação. De fato, é o neointervencionismo do Estado que, sob os escombros fluídos do derretimento e liquidez do capital em crise, se faz explícito, declarado e reconhecido pelos arautos do neoliberalismo, fiéis devotos do livre mercado.

Assim, o discurso dominante no final da primeira década do século $\mathrm{XXI}$, proclama 0 regresso do Estado, ou seja, a volta do Estado como ator importante e decisivo. A pedra de toque no desvendamento deste momento na civilização do capital é ter clareza que o neointervencionismo do Estado - hoje, explícito nos circuitos de crise e, velado, no passado recente de dominância neoliberal - constitui elemento decisivo nos processos de acumulação e valorização do capital nos percursos da mundialização e seus ciclos de ajuste (CARVALHO, 2010). Neste sentido, István (Mészáros, 1997) é categórico: o sistema capitalista não sobrevive um dia sequer, sem uma das múltiplas formas de intervenção massiva do Estado. Inegavelmente, o Estado é um dos elementos do 
núcleo constitutivo do sistema de sociometabolismo do capital (MÉSZÁROS, 2002), atuando, de formas específicas e peculiares, nos diferentes momentos de desenvolvimento da civilização do capital.

Logo, o alardeado regresso do Estado é um falso regresso, ou melhor dizendo, encarna o paradoxo do regresso sem partida (CARVALHO, 2010). A rigor, a proclamação de tal regresso não é senão a volta do Estado ao centro da cena pública, a partir do desmonte da mitologia neoliberal do livre mercado a regular a vida social.

A questão decisiva em pauta é a incapacidade deste neokeynesianismo, via intervenção financeira maciça do Estado e das instituições globais, para resolver a crise. A rigor, novas regulações do capitalismo-como querem determinadosorganismos internacionais e proclamam ideólogos do capital não constituem alternativa de solução para essa crise global do sistema do capital na condição de uma crise sistêmica. Assim, os detentores do capital e os trabalhadores são confrontados à ineficácia das medidas institucionais de enfrentamento da crise estrutural do capital que se desloca e se aprofunda, revolucionando a morfologia social do trabalho.

Arigor, uma dimensão chave da crise estrutural e sistêmica do capital é a corrosão do trabalho, com fortes expressões em nações europeias, atingidas nos circuitos da crise, nos Estados Unidos e com fortes repercussões no mundo do trabalho em escala global. É neste cenário que se afirma, como fenômeno contemporâneo, a precarização estrutural do trabalho, a consubstanciar uma

[...] nova forma de precarização do trabalho, que perpassa as experiências vividas de trabalhadores e trabalhadoras na sua vida cotidiana e que diz respeito à estrutura da própria práxis humana. (ALVES, 2013, p.10).

\section{PRECARIZAÇÃO ESTRUTURAL DA FORÇA} HUMANA QUE TRABALHA: marco da nova temporalidade histórica do sistema do capital no século $X X I$

Hoje, sem paralelos em toda a era moderna, acirra-se, na civilização contemporânea do capital, a contradição circunscrita por Marx, nos Grundrisse [1857-1858] (2011): a crescente substituição do trabalho vivo de homens e mulheres pelo trabalho morto, objetivado nas máquinas. A rigor, o sistema do capital, ao apropriar-se das conquistas da Revolução Técnico-Científico-Informacional ${ }^{5}$, efetiva o revolucionamento do homem-e-da-técnica, ou, o revolucionamento da própria relação homemtécnica, constituindo o que Giovanni Alves (2013) conceitua de maquinofatura, como terceira forma de produção social do capital $^{6}$, circunscrevendo o novo (e precário) mundo do trabalho, ao longo dos trinta anos perversos do capitalismo global, nos marcos de uma acumulação flexível, dentro de um novo padrão de precarização da força humana que trabalha. Este revolucionamento homem-técnica, efetivado pelo "[...] capital-máquina, visa constituir um novo nexo psicofísico e metabolismo social que permita a constituição de homens com pensamentos mais conformistas." (ALVES, 2013, p. 24). Desse modo, com a maquinafatura constitui-se o homo tecnologicus, a encarnar a ciberhominização. Repõese, num plano virtual, a máquina como instrumento e o homem como vigia da máquina:

Na verdade, tendo em vista que se trata
de reposição meramente virtual, isto é,
posição de possibilidades contraditórias
contidas na nova base técnica, o novo
homem que surge como 'homem
tecnológico' é um feixe de contradições
reais (o virtual é um modo de ser do real
efetivamente contraditório). (ALVES,
2013, p. 26).

Adentrando nesta nova forma de produção social do capital, consubstanciada na maquinafatura, constata-se que, em sua nova temporalidade histórica, o sistema do capital, com a mediação da ciência e da tecnologia, vai prescindindo da presença física e do próprio saber e do próprio fazer do trabalhador, com o predomínio das chamadas máquinas inteligentes, nos circuitos cibernéticoinformacionais, incorporadas a redes digitais. Gesta-se, assim, o crescimento e a ampliação da precariedade laboral, materializada no desemprego e nos múltiplos processos de precarização, a alastrar-se no conjunto da classe trabalhadora, em seus distintos segmentos e diferentes categorias profissionais.

Graça Druck (2009), no intuito de captar, com mais precisão, modalidades de precarização em curso no mundo do trabalho na contemporaneidade do sistema do capital, categoriza cinco tipos que delineiam vias de investigação: precarização das formas de mercantilização da força de trabalho; precarização da organização e das condições de trabalho; precarização das condições de segurança no trabalho; precarização das condições de representação e organização sindical; precarização do processo de construção das identidades individual e coletiva. É preciso enfatizar que esta precarização laboral ampliada adentra os diferentes domínios da vida, capturando a própria subjetividade dos homens e mulheres trabalhadores(as), nesta nova ordem do capital. Assim, a precarização do trabalho que ocorre hoje, no século XXI, sob o capitalismo global, seria não apenas precarização do trabalho, no sentido da força-de-trabalho como mercadoria, mas seria também a precarização do homem-quetrabalha, no sentido de precarização existencial, atingindo o homem como ser genérico. Com efeito, tem-se uma precarização que se amplia e se difunde, 
a perpassar a relação trabalho-vida. Giovanni Alves assim explicita a constituição desta precarização estrutural que marca os tempos contemporâneos:

A nova precariedade salarial, ao alterar a dinâmica da troca metabólica entre o espaço-tempo de vida e espaço-tempo de trabalho, em virtude da "desmedida" da jornada de trabalho, corrói o espaçotempo de formação de sujeitos humanogenéricos, aprofundando, desse modo, a autoalienação do homem-quetrabalha. Nesse caso, transfigura-se a cotidianidade de homens e mulheres que trabalham com a redução da vida pessoal a mero trabalho assalariado (ALVES, 2013a, p. 86-87).

Em verdade, na temporalidade histórica da crise estrutural do capital, no século XXI, constituise uma nova forma de precarização estrutural do trabalho: é a precarização da força de trabalhosubsumida-ao-sistema-de-máquinas. A rigor, a precarização do homem-que-trabalha, nos circuitos do capitalismo global, explicita à exaustão o estranhamento dos indivíduos, o seu completo esvaziamento. Esclarece Alves (2013) que esta precarização, ao atingir o trabalho e a própria vida do homem-que-trabalha, produzindo a desefetivação do ser genérico do homem, implica a corrosão da capacidade humana de negação da negação da alienação e do estranhamento social. De fato, tem-se a captura da subjetividade do homem-que-trabalha, intensificando o estranhamento social, com novas formas que dilaceram o núcleo humano genérico. $E$ conclui Alves (2013a, p. 10; 26:

[...] é a forma radical de dominação do capital como sistema sociometabólico [...] o capital atinge seu limite radical, isto é, o capital atinge a sua própria raiz, o homem, ou melhor, as relações sociais no sentido da constituição/deformação do sujeito histórico como homem-que-trabalha.

De fato, no seio da maquinofatura, o capitalismo manipulatório mantém sob tensão o homem integral. Concretamente, homens trabalhadores e mulheres trabalhadoras vivenciam a precarização laboral e a precarização da própria existência, comprometendo a saúde, a perspectiva de vida e a inserção na totalidade das relações sociais. O sofrimento no trabalho, sob múltiplas formas, leva ao adoecimento físico e mental, com doenças características da epidemiologia laboral. Neste contexto da maquinofatura, a produção do capital torna-se totalidade social e o estranhamento que, antes só ocorria no trabalho, adentra o campo do lazer. A rigor, o lazer torna-se meramente um momento de subjetivação estranhada do capital. (ALVES, 2013a) Lazer é consumo. E o consumismo torna-se uma forma de existência social. $\mathrm{Na}$ era do capitalismo manipulatório, em tempos contemporâneos, o estranhamento alarga-se para esferas do lazer e do consumo. Em verdade, com a terceira forma de produção social do capital, temse uma disputa, de forma radical, pela subjetividade de homens e mulheres que trabalham, fazendoos indivíduos rendidos à manipulação do capital. $\mathrm{E}$, essa manipulação da subjetividade gesta uma disputa íntima, a dilacerar homens trabalhadores e mulheres trabalhadoras nas suas experiências de vida, transfigurando o seu cotidiano, reduzindo e restringindo seu espaço-tempo de vida. É emblemático desta nova temporalidade do capital o surto de adoecimentos mentais no mundo do trabalho. Em suas novas configurações, o processo de precarização do trabalho, nas condições da crise estrutural do capital, assume a dimensão da barbárie social (ALVES, 2013a).

No esforço de apreensão e desvendamento desse novo e precário mundo do trabalho, na civilização do capital em crise, Giovanni Alves (2012; 2013) circunscreve uma fecunda via analítica, ao demarcar, como um fenômeno contemporâneo, no decorrer dos trinta anos perversos de capitalismo global (décadas de 1980/1990/ anos 2000): a universalização da condição de proletariedade ${ }^{7}$, como condição existencial de homens e mulheres que vivem sob a ordem burguesa, no contexto da maquinofatura e da precarização estrutural da força humana-que-trabalha. A rigor, significa a universalização da precarização do trabalho, cada vez mais estranhado, e da vida estranhada a que homens e mulheres que trabalham estão submetidos na maquinofatura, sob a égide do sistema-máquina e da mercantilização exacerbada, tendo o consumismo como forma de existência. Esta universalização da condição de proletariedade, como condição de existência (des)humana, encarna-se em uma série de atributos histórico-existenciais que se disseminam na civilização contemporânea do capital em crise: instabilidade, insegurança, descontrole existencial, incomunicabilidade, corrosão do caráter, deriva pessoal e sofrimento, risco e periculosidade, experimentação e manipulação, prosaísmo e desencantamento, ausência de projeto de vida, resignação. Tais atributos existenciais da condição de proletariedade

[...] permeiam as múltiplas relações sociais no sistema do capital em tempos de capitalismo global, tornando-se atributos da vida social estranhada. Assim, a universalização da condição de proletariedade acompanha o movimento voraz do capital, a constituir a chamada "modernidade-mundo" (ALVES, 2013a).

Que marca a nova temporalidade histórica na contemporaneidade.

No contexto da universalização da condição de proletariedade, a estender-se no âmbito do 
capitalismo global, emerge e constitui-se a nova camada social da classe trabalhadora: o precariado, a manifestar-se, com intensidade e amplitude, nos considerados países capitalistas centrais, com destaque para União Europeia, Estados Unidos e Japão. A rigor, o precariado é um enigma que permeia o sistema do capital em crise a interpelar a imaginação dialética. O precariado é a multidão da era do capitalismo global, do capitalismo flexível que marca as últimas décadas do século $X X$, adentrando no século XXI com flexibilidade desdobrada, a assumir novas proporções, intensidade e amplitude.

A rigor, quem é este precariado e como se circunscreve no cenário contemporâneo, na condição de uma camada social de classe? É esta uma questão preliminar a remeter a uma descrição de atributos de vida, a uma configuração de traços históricos no plano da existência social. Senão vejamos!

São milhões de trabalhadores jovens-adultos com alta escolaridade, desempregados ou inseridos em contratos de trabalho precários que transitam de uma ocupação a outra, quase sempre com baixos salários, sem projetos de vida e perspectiva de futuro. É uma multidão de jovens proletários assalariados, vinculados a camadas médias, com níveis elevados de qualificação profissional, entrando e saindo de empregos precários, a viver em situação de insegurança econômica e social, sem identidade ocupacional, sem garantia de direitos e tomados pelo sentimento de ansiedade perante o futuro. É uma camada da classe trabalhadora em construção, a vivenciar a precarização do trabalho e da própria vida, precisamente nesta articulação contemporânea entre faixa geracional (jovens-adultos), grau educacional (alta escolaridade) e forma de inserção no trabalho e no mundo social (precarizada, instável e insegura)(ALVES, 2012a; 2013a; 2013b; 2013c).

No mundo do capital em seu tempo histórico de crise estrutural, o proletariado circunscreve uma coletividade de despojados, sendo identificados, no caso da Geração à Rasca de Portugal, como a Geração Sem-Sem: sem trabalho, sem casa, sem acesso a direitos... ou, então, como na condição dos Indignados, na Espanha, como a Geração NiNi: ni estudia, ni trabaja. Enfim, ser precário, neste mundo do trabalho flexível, instável, marcado pela liquidez e pela radical insegurança, é ter um futuro continuamente hipotecado, com a impossibilidade de fazer planos, vivendo imerso no dia a dia, no aqui e no agora, quase no hora-a-hora (ALVES, 2012a; 2013a). Em verdade, tem-se em curso um novo modo de controle sociometabólico do capital, operando fraturas salientes na experiência do tempo social, fazendo emergir o fenômeno da presentificação crônica que atinge fortemente o precariado. Milhões de trabalhadores jovens-adultos, vivem numa espécie de presentismo contínuo, sem uma relação orgânica com o passado público da época em que vivem e sem perspectiva de futuro.
Assim, o precariado configura-se em grupos de juventudes frustradas e revoltadas que se disseminam mundo afora, sobremodo nos países capitalistas globais, nos circuitos da crise, unificados pela insegurança, pelo medo, risco e desencantamento e pela indignação a expressar-se de forma crescente. Este precariado encarna o perigo de uma Bolha Educacional Global (STANDING, 2013; ALVES, 2013): milhões de jovens-adultos com níveis elevados de qualificação profissional, que tiveram seus sonhos de inserção salarial frustrados pela nova dinâmica do capitalismo global, encarnando a frustração com a educação como via de inserção no mundo do trabalho.

Em verdade, este precariado é uma expressão peculiar, no contexto das juventudes, do crescente contingente de trabalhadores supérfluos - a chamada população sobrante a tentar equilibrarse no fio da navalha das exclusões e inclusões precárias - gestado pelo sistema do capital que, como contradição em processo, nesta sua nova temporalidade histórica, atingiu um estágio em que é necessário expulsar centenas de milhões de homens e mulheres do próprio processo de trabalho, tornando-os supérfluos ao seu modo de funcionamento e revelando-se incapaz de incluir esta população sobrante, condenando, assim, amplos contingentes de trabalhadores à redundância social (CARVALHO, 2012a). E o tornar-se supérfluo para juventudes, na condição de um exército global de excedentários, imersos na insegurança do presente e sem perspectivas de futuro, constitui uma enfática autocondenação do próprio sistema do capital, desvelando a natureza estrutural da sua crise (MÉSZÁROS, 2009).

De fato, o

"[...] surgimento e ampliação do precariado expõe a verdadeira natureza da crise estrutural, isto é, a contradição radical entre desenvolvimento das forças produtivas e irrealização estrutural das promessas civilizatórias do capital" (ALVES, 2013a, p.196).

Assim, o precariado, ao dar visibilidade candente à condição de proletariedade, como condição existencial a universalizar-se no mundo social do capital em processo de crise estrutural, afirma-se como a expressão social suprema do estranhamento, aviltando e dilacerando o desenvolvimento da personalidade humana de milhões de jovens-adultos que se percebem sem rumo, sem perspectiva e sem projeto de vida, em meio a uma crescente precarização existencial.

3 PRECARIADO: afinal, do que se trata?

O precariado, a mundializar-se no século XXI, ganha visibilidade no cenário contemporâneo, afirmando a sua condição de proletariedade, 
na era do capitalismo flexível, manipulatório, a incomodar as classes dominantes e a tensionar governos submetidos à agenda de ajuste, na vã tentativa de enfrentamento da crise do capital, em seus permanentes deslocamentos. A rigor, nos circuitos da crise, a multidão do precariado irrompe, com intensidade e amplitude, na semiperiferia do núcleo orgânico do sistema do capital - a exemplo de Portugal, Espanha, Itália e Grécia - onde se explicitam, com vigor, contradições mais candentes da ordem burguesa. No entanto, ao mostrar a sua universalidade, como expressão peculiar da crise do capital, o precariado emerge, com força, no coração do Império da acumulação rentista, os EEUU, mais especificamente em Wall Street, denunciando a sua precarização estrutural, no âmbito do trabalho e da própria existência social estranhada, no contexto de assimetrias e desigualdades que peculiarizam a vida social norte-americana. E, o precariado eclode em países da América Latina, denunciando a condição de precariedade a partir de diferentes bandeiras de luta. E chega ao Brasil, em junho/julho 2013, no acirramento de contradições que se manifestam na gestão das cidades nas rotas do capital, a encarnar o então denominado padrão FIFA, em meio às tensões da Copa das Confederações em território brasileiro. Enfim, com formas peculiares de expressão pública e de questionamentos ao capitalismo global e à política institucionalizada, o precariado revela-se na cena pública, na sua luta por reconhecimento como sujeito social, constituindo uma rede de movimentos transnacionais, reunidos pela frustração e indignação, a exigir redefinições nos governos, reviravoltas no sistema do capital, radicalidade na democracia e a afirmar novas formas do fazer político.

De fato, o precariado é uma multidão global em expansão, encarnando um segmento que confere visibilidade à condição de proletariedade do capitalismo mundializado e suas formas de trabalho e vida estranhada. É significativa a sua participação no Extremo Oriente - com destaque para o Japão e a Coréia do Sul - a constituir uma potencial força, gestada no limite das contradições, representando um campo de tensões a se acumularem, expressando-se em ansiedade, raiva, insegurança, frustração e indignação.

\subsection{Adentrando na polêmica conceitual: precariado, um conceito em disputa}

A análise do precariado, como desafio do nosso tempo histórico, circunscreve um campo de discussão e de investigação. Em verdade, tem-se um conceito em disputa, com diferentes sentidos e distintas vertentes explicativas ${ }^{8}$. O cerne do debate conceitual é, justamente, a natureza do precariado na condição de segmento social em consolidação na civilização contemporânea do capital. Trata- se de uma nova classe social ou de uma camada específica da classe trabalhadora ou, o precariado é uma configuração conceitual para designar os trabalhadores precarizados neste mundo do trabalho em mutações, mais especificamente, o proletariado precarizado. É essa uma polêmica circunscrita nas construções analíticas de três pesquisadores, com produções acadêmicas, inclusive livros específicos, trabalhando a questão do precariado, ou melhor, colocando o precariado em questão: Guy Standing ${ }^{9}$, que abre o debate com sua obra The Precariat: The New Dangerous Class de 2011, publicada em português em 2013, com o título O Precariado: a nova classe perigosa; Giovanni Alves ${ }^{10}$ que, em 2012, publica no site da Boitempo, uma sequência de estudos $O$ enigma do precariado e a nova temporalidade histórica, sendo o autor da obra Dimensões da Precarização do Trabalho, publicada em 2013, e, igualmente, em 2013, produz artigos sobre o precariado no Brasil e sua revolta nas manifestações de junho/julho; Ruy Gomes Braga Neto ${ }^{11}$ autor da obra A Política do Precariado: do populismo à hegemonia lulista, publicada em 2012, produzindo, em 2013, artigos sobre as rebeliões juvenis.

Abrindo o debate no campo acadêmicopolítico, Guy Standing, a partir de apresentações em dezesseis países para grupos de acadêmicos, estudantes e ativistas, consolida, em sua obra de 2011, a concepção do precariado como uma classeem-formação, dividida entre grupos revoltados e frustrados, mas unidos pela insegurança e pelo medo. Identifica, então, como os três principais grupos que compõem o precariado: imigrantes e membros de minorias, sem acesso a direitos e renda estável; jovens com ensino superior frustrados e sem expectativas profissionais; filhos de mineiros, metalúrgicos, estivadores e outras profissões típicas do capitalismo industrial, sem a opção de seguir as carreiras dos pais, ocupando postos de menor status (STANDING apud CAZES, 2013) ${ }^{12}$. Considera ser esta uma classe perigosa que pode desenvolver, como possibilidade perturbadora, uma política de inferno, podendo, também, forjar uma nova política de paraíso, desde que se torne uma classe-para-si. Esclarece Standing (2013) que não se trata da 'classe média oprimida ou de uma classe baixa, tampouco da classe trabalhadora mais baixa. E sustenta que o precariado tem um fardo distintivo de insegurança e um conjunto diferente de reivindicações, possuindo uma existência precária. Vincula a emergência e expansão do precariado ao modelo neoliberal e sua agenda centrada na competitividade do mercado, a permear todos os aspectos da vida. Assim, avalia Standing (2013, p. 15)

Um dos temas era que os países deveriam aumentar a flexibilidade do mercado de trabalho, o que passou a significar uma agenda para a transferência de riscos e insegurança 
para os trabalhadores e suas famílias. $\mathrm{O}$ resultado tem sido a criação de um "precariado" global, que consiste em muitos milhões de pessoas ao redor do mundo sem uma âncora de estabilidade. Eles estão se tornando uma nova classe perigosa.

Eé contundente em seu alerta: "[...] precisamos urgentemente acordar para o precariado global. Há muita raiva por aí e muita ansiedade". (STANDING, 2013, p.11).

Em sua construção conceitual, Guy Standing circunscreve o precariado como classe-emformação, a partir da insegurança no trabalho em suas múltiplas formas, destacando, como um elemento-chave, a falta de uma identidade segura baseada no trabalho. E sintetiza que o precariado sofre do que, em inglês, chamamos de quatro $A$ : raiva (anger em inglês), anomia, ansiedade e alienação. E explicita:

\begin{abstract}
A raiva decorre tanto da frustração diante das vias aparentemente bloqueadas para promover uma vida significativa quanto de um sentimento de relativa privação [...] $\mathrm{O}$ precariado se sente frustrado não só por causa de toda uma vida de acenos de empregos temporários, com todas as inseguranças que vêm com eles, mas também porque esses empregos não envolvem nenhuma construção de relações de confiança desenvolvidas em estruturas ou redes significativas. O precariado também não tem nenhum meio de mobilidade para ascender, o que deixa a pessoa em suspenso entre a profunda autoexploração e o desengajamento (STANDING, 2013, p. 41).
\end{abstract}

Giovanni Alves, em sua construção analítica marxista, em fidelidade à ampliação conceitual da dialética, concebe o precariado não como uma classe emergente, mas, sim, como uma camada social da classe do proletariado, constituída na convergência categorial de três variáveis: faixa etária, escolaridade e inserção salarial (ALVES, 2012; 2013a; 2013b; 2013c; 2013d). Assim, o precariado em Alves, como camada social da classe do proletariado, está circunscrito a um segmento específico: jovensadultos, altamente escolarizados, inseridos em relações salariais precárias. $\mathrm{E}$, em um processo de aproximações, buscando dar maior precisão teórica a cada variável, no sentido de conferir precisão categorial ao conceito, Alves explicita:

Juventude - O precariado é uma camada social constituída pela juventude. Esta é a percepção imediata da categoria: trata-se de um fenômeno social de classe predominantemente juvenil. Pergunta-se: nesse caso, qual a faixa etária que caracterizamos a juventude? Ora utilizamos o termo "jovens", outras vezes, "jovens-adultos". $\mathrm{Na}$ verdade, existem controvérsias sobre o conceito de juventude. O que é ser jovem? O que é ser jovem-adulto? Em termos de faixas etária, podemos estabelecer o seguinte: dos 18 aos 35 anos de idade podem ser considerados jovens-adultos. Não se trata de demarcação biológica, mas sim sócio-cultural [...]

Escolaridade - O precariado é uma camada social constituída por jovensadultos altamente escolarizados. Não se trata meramente de escolarização formal, mas sim de um tipo específico de escolarização que propicia a formação de expectativas de inserção ocupacional de qualidade capaz de garantir a realização dos anseios e sonhos da civilização burguesa: carreira profissional, consumo e família. Nesse caso, a escolarização capaz de elevar as expectativas de realização pessoal como trabalhador assalariado, consumidor e chefe de familia - ideais burgueses - tem sido a escolarização superior (teoria do capital humano). É claro que o ensino técnicoprofissionalizante poderia ser também um tipo de escolarização formadora de expectativas de realização pessoal do homem burguês, na medida em que propicia reconhecimento social, status e prestígio capaz de significar a efetivação - no plano dos anseios, sonhos e expectativas - dos ideais burgueses que caracterizaram a fase de ascensão histórica do capital (o capitalismo fordista-keynesiano). Por outro lado, o ensino médio é apenas a etapa inicial da escolarização capaz de elevar as expectativas de inserção ocupacional gratificante para a afirmação do homem burguês[...]

Inserção salarial - o precariado é a camada social inserida em atividades salariais precárias. Com a crise do padrão fordista-keynesiano de contratação salarial, surge uma série de modalidades contratuais precárias que danificam o elo tempo presente-tempo futuro das individualidades pessoais de classe. A frustração das expectativas se realiza com a inserção precária no mercado de trabalho. $\mathrm{Na}$ verdade, as empresas "implodem" o ideal de carreira profissional, tornando intermitente a trajetória do sujeito, ampliando o campo da insegurança pessoal no que diz respeito a emprego e renda. É o tema da precarização do trabalho que possui não apenas um componente de precarização salarial, mas também um componente de precarização existencial, precarização do homemque-trabalha. Deste modo, a inserção 
precária do precariado não é apenas salarial no sentido restrito, mas possui um elemento existencial - trata-se de uma inserção precária nas relações de trabalho e de vida: trabalho precário e vida precária no tocante à reprodução social (o precariado está imerso na precarização dos serviços públicos de educação e saúde, sendo manipulados intensamente pelo consumo, produção e política) (ALVES, 2013d, p.1 e 2) ${ }^{13}$.

Ruy Braga, em uma interpretação marxista, define o precariado como proletariado precarizado, ampliando o conceito para os trabalhadores precarizados, enfatizando a precariedade como dimensão intrínseca do processo de mercantilização do trabalho. Explicita ele como fundamento da sua construção conceitual:

[...] entendemos que em decorrência da mercantilização do trabalho, do caráter capitalista da divisão do trabalho e da anarquia da reprodução do capital, a precariedade é constitutiva da relação salarial. Consequentemente, o precariado não deve ser interpretado como o antípoda do salariado, seu "outro" bastardo ou recalcado. $\mathrm{Na}$ realidade, ele é a própria condição de existência do salariado: tanto na Europa ocidental quanto nos Estados Unidos, o compromisso fordista mostrou-se bastante eficiente em proteger a fração profissional, branca, masculina, adulta, nacional e sindicalizada da classe trabalhadora, à custa da reprodução da fração proletária não qualificada ou semiqualificada, feminina, negra, jovem e migrante. (BRAGA, 2012, p.17)

E delineia, então, uma concepção ampla e generalizante do precariado:

[...]poisentendemosqueostrabalhadores precarizados são uma parte da classe trabalhadora em permanente trânsito entre a possibilidade da exclusão socioeconômica e o aprofundamento da exploração econômica [...] A necessidade de definir os limites gerais do precariado nos obriga também a diferenciá-lo dos setores profissionais, ou seja, aqueles grupos mais qualificados, mais bem remunerados e, por isso mesmo, tendencialmente mais estáveis, da classe trabalhadora. Em suma, identificamos o precariado com a fração mais mal paga e explorada do proletariado urbano e dos trabalhadores agrícolas, excluídos a população pauperizada e o lumpemproletariado, por considerá-la própria à reprodução do capitalismo periférico. (BRAGA, 2012, p.19). enigma contemporâneo

Neste esforço reflexivo de adentrar na polêmica conceitual do precariado no debate contemporâneo, vê-se que, de fato, é esta uma categoria em disputa. Incidindo o foco analítico nos três pesquisadores em pauta, constata-se uma discordância de fundo entre Guy Standing e os dois pesquisadores - Giovanni Alves e Ruy Braga - na condição de investigadores que trabalham no campo do marxismo, a mobilizarem a imaginação dialética: é, precisamente, no tocante à natureza do precariado no contexto da civilização do capital. Para Alves e Braga não se trata de uma classe nova - como defende Standing - e, sim, de um segmento, uma camada social do proletariado. A questão-chave é, então, delimitar a constituição do precariado. Braga amplia a concepção de precariado para o proletariado precarizado, identificando-o como a fração mais mal paga e explorada do proletariado urbano e trabalhadores agrícolas, inclusive, em certos aportes, vinculando-o à baixa qualificação. E, nesta ampliação da constituição do precariado, existe uma aproximação com Standing que, na composição do precariado, identifica imigrantes e membros de minorias, jovens do ensino superior frustrados e filhos de profissionais típicos do capitalismo industrial. Já Giovanni Alves, buscando dar conta de um fenômeno da nova temporalidade do capital em crise, circunscreve o precariado a um grupo específico: jovensadultos, altamente escolarizados, inseridos em relações salariais precárias. Avalio que a ampliação do precariado para o contingente de trabalhadores precarizados, no mundo do trabalho contemporâneo, compromete a capacidade explicativa desta categoria analítica, desfocando o fenômeno marcante nesta temporalidade histórica do capital que é, justamente, estas juventudes e este amplo e crescente segmento de jovensadultos qualificados, com precária inserção no mundo do trabalho e na própria vida social, mergulhados na insegurança e sem perspectiva de presente e de futuro. Deste modo, com esta ampliação, o conceito de precariado perde o seu poder explicativo, no sentido da teorização nos circuitos da História. Assim, como pesquisadora a situar-me nesta polêmica conceitual, assumo, como base de minhas investigações sobre 0 precariado, a vertente analítica de Giovanni Alves, consciente do que o próprio pesquisador destaca, no sentido de que se tem, em curso, processo de entendimento do fenômeno precariado, efetivandose aproximações categoriais, a exigir permanente crítica e autocrítica (ALVES, 2013c; 2013d).

Nas trilhas analíticas de GiovanniAlves, merece destaque na configuração conceitual do precariado, a sua precariedade ampla e ampliada, a encarnar a universalização da condição de proletariedade. De fato, o precariado, como verdadeira contradição viva, está exposto, com maior intensidade, à manipulação da ordem burguesa e por isso vive, 
com maior intensidade, a precarização do trabalho, tanto no sentido da precarização salarial, quanto no sentido de precarização existencial (ALVES, 2013b). E explicita Alves:

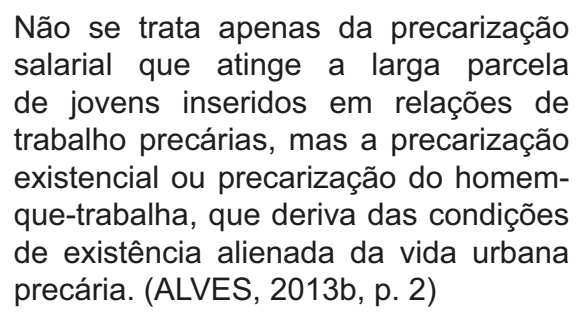
salarial que atinge a larga parcela de jovens inseridos em relações de trabalho precárias, mas a precarização existencial ou precarização do homemque-trabalha, que deriva das condições de existência alienada da vida urbana precária. (ALVES, 2013b, p. 2)

Assim, a precarização existencial - que se hibridiza à precarização salarial - implica a precarização da circulação e da mobilidade urbana precária, a precarização do tempo de vida assolado pelos requisitos do trabalho estranhado e, no tempo livre, manipulado pelo consumo e o lazer superficial e alienante. E conclui:

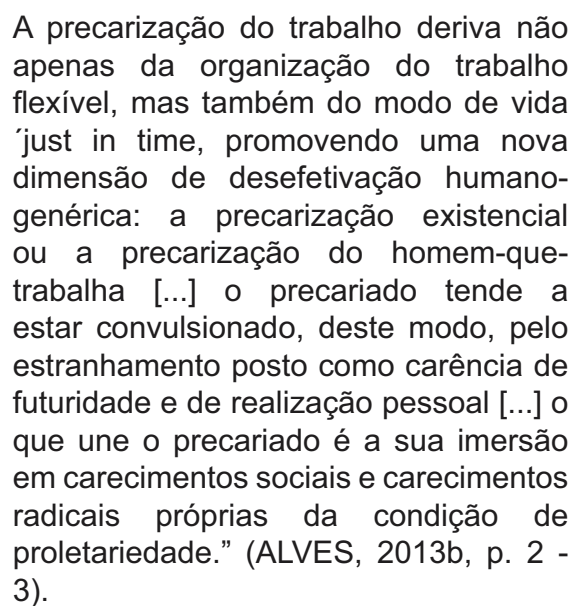

O precariado, imerso na precariedade salarial e na precaridade existencial, incorpora a ideologia do capitalismo global, encarnando os valores-fetiches da mercantilização e do individualismo. A rigor,

"[...] no plano da consciência social contingente, a 'geração precária' possui uma consciência liberal, tendo em vista que são plenamente 'sujeitos monetários' que habitam a metrópole com seus templos de consumismo." [...] (ALVES, 2013, p.203).

É a geração $Y$, a encarnar a manipulação intensiva e extensiva na sociedade em rede. De fato, o precariado tornou-se alvo privilegiado do poderio da ideologia na ordem burguesa global, a operar, principalmente, no espectro moral-intelectual. Em meio a esta manipulação, no limite do trabalho e da vida estranhados, o precariado encarna reações contra-hegemônicas, sendo emblemáticos os seus movimentos sociais que buscam criticar, de modo coletivo, em sua peculiaridade, a ordem da precarização estrutural do trabalho. Em verdade, o precariado é a contradição em processo, impondo ao pensamento crítico uma ampla via de investigação sobre a sua subjetividade, no sentido de captar os movimentos da ideologia, a operarem nos corações e mentes desta geração precária, no contexto de um capitalismo manipulatório em crise.

4 O PRECARIADO NO BRASIL: uma via investigativa em aberto

Cabe destacar que, no chamado capitalismo periférico, no âmbito dos processos mundiais de acumulação, particularmente no Brasil, a precarização laboral não é um fenômeno novo, caracterizando a sociedade urbana industrial desde as suas origens. No entanto, nos últimos trinta anos e, de forma peculiar, no século $X X I$, este fenômeno histórico assume novas configurações e expressões, alastrando-se no interior do capitalismo global, nos mais diferentes contextos, sobremodo a partir da deflagração da crise estrutural do capital, no final da primeira década dos anos 2000. Assim, circunscreve-se, no contexto brasileiro, o que se pode nomear de morfologia social do trabalho nos anos 2000, encarnando uma nova precariedade salarial (ALVES, 2012b). É neste cenário que emerge e constitui-se o precariado no Brasil, em suas expressões peculiares, constituído por um conjunto de categorias sociais: estudantes de nível médio ou nível superior, recém-graduados desempregados ou inseridos em relações salariais precárias; ou ainda por jovens empregados precarizados (ALVES, 2013c).

O desvendamento crítico da emergência, constituição e expressões peculiares do precariado na cena brasileira remete, necessariamente, a uma análise do momento contemporâneo do capitalismo no Brasil, discutindo as expressões da crise do capital entre nós e a atual inserção brasileira nos processos do capitalismo financeirizado. É a exigência analítica de adentrar no Brasil que se constitui nas tramas das políticas de ajuste e no neodesenvolvimentismo, a desvendar o modelo brasileiro rentista-extrativista, centrado na financeirização dependente, no extrativismo intensivo das riquezas naturais, a ancorar a dinâmica macroeconômica no consumo e o consumo no crédito (CARVALHO, 2013a; 2013b; CARVALHO; CASTRO, 2013) $)^{14}$.

Neste Brasil do século XXI de dependência redobrada, nos circuitos da financeirização e do chamado neodesenvolvimentismo, Giovanni Alves (2012b), ao analisar a nova morfologia social do trabalho, com o surgimento de um novo metabolismo laboral, destaca que, no contexto brasileiro, apesar do crescimento do emprego por tempo indeterminado e da redução da taxa de informalidade a partir de 2003, a nova precariedade salarial manifestou-se pelo aumento, em termos absolutos e relativos, da presença de trabalhadores periféricos, inseridos em relações de trabalho precárias. De forma inconteste, 
o fenômeno da terceirização cresceu, no Brasil, nos anos 2000, atingindo tanto o setor privado quanto o setor público. E, esclarece Alves (2012b, p. 6) que

"[...] a nova precariedade salarial no Brasil se manifesta, não apenas pelo aumento da contratação flexível, mas também pela adoção, nos locais de trabalho reestruturados, da flexibilização da jornada de trabalho e da remuneração salarial"15.

Assim, o precariado, nesta nova temporalidade do capital, afirma-se no Brasil com expressões específicas e encarnações particulares. Neste sentido, cabe destacar duas encarnações emblemáticas da geração precária na vida brasileira do século XXI: amplo segmento de profissionais com nível superior, atuante em instituições públicas e no chamado Terceiro Setor, a vivenciar múltiplas formas de precarização do trabalho, sobremodo nos circuitos da terceirização e de precarização da vida, mergulhado no risco e na insegurança econômica e social (CARVALHO, 2012); os teleoperadores da indústria de call center e sua inserção laboral intensamente precarizada, atingindo e comprometendo a saúde e a vida desses trabalhadores(as).

Adentrando no universo de trabalho e de vida do precariado brasileiro, constata-se a precarização ampliada do trabalho, circunscrita por Alves (2013a; 2013b; 2013c; 2013d): precarização salarial em suas múltiplas expressões, com destaque para o desemprego e ocupações transitórias e fluidas, rotatividade do trabalho, contratos precários, baixos salários, frustração de expectativas de carreira; precarização existencial, encarnado no padrão de vida estranhado, atingindo e comprometendo a humanidade de homens-e-mulheres-que-trabalham. São jovens-adultos carentes de vida com sentidos, projetos e utopias, carentes de vida plena. Esta precarização existencial manifesta-se na conjugação de distintas dimensões, cabendo enfatizar: modo de vida em ritmo acelerado, vidas no limite e no risco, imersas no presentismo e sem perspectivas de futuro; tempo de vida submetido aos requisitos do trabalho estranhado e tempo livre manipulado pelo consumo e pelo lazer superficial e alienante; condições de vida urbana precarizada com a precariedade de serviços públicos nas cidades brasileiras: transporte público, saúde, educação, segurança pública, lazer, espaços públicos de convivência. Enfim, são carecimentos radicais de futuridade e de realização pessoal, atingir estes jovens-adultos escolarizados e com inserção precária nas relações de trabalho e na vida social, tornando-os vulneráveis ao desalento, à angústia, à frustração, à ansiedade perante o futuro à indignação e ao desespero.

É este precariado brasileiro que se constitui e se amplia no Brasil do século XXI, despojado de perspectivas de presente e de futuro que foi às ruas em junho/ julho de 2013, em mais de trezentas e cinquenta cidades brasileiras, constituindo rebeliões juvenis. Sustenta Giovanni Alves (2013d, p. 1) que a "[...] onda massiva de protestos que assistimos nas cidades brasileiras é o que poderíamos considerar como sendo a revolta do precariado". E afirma categórico que "[...] o precariado é a espinha dorsal dos protestos nas ruas das cidades brasileiras". (ALVES, 2013c, p.1).

\section{PRECARIADO NOS CIRCUITOS DAHISTÓRIA:}

uma aposta em aberto

Em meio a polêmicas e discussões, impõese uma reflexão fundante: qual a perspectiva do precariado nos movimentos da História? Qual o seu futuro? Para onde o precariado está a levar a civilização do capital em crise?

Para avançar nesta reflexão políticoontológica, em aberto, cabe delinear elementoschave na constituição do ser do precariado, nesta temporalidade histórica de crise estrutural do capital. Nessa perspectiva, cabe demarcar a sua contraditoriedade constitutiva que Giovanni Alves (2013b, p. 2) assim explicita:

É importante salientar que o precariado como camada social do proletariado é, em si e para si, profundamente contraditório, tendo em vista que ele incorpora as contradições candentes da ordem do capital em sua etapa de crise estrutural. Na medida em que o precariado é constituído por jovens altamente escolarizados, ele tende, por um lado, a incorporar a contradição radical entre, por um lado, os sonhos de consumo e anseios de ascensão social, e por outro, os carecimentos radicais inscritos na busca por uma vida plena de sentido - carecimentos radicais incapazes de serem realizados no seio da ordem burguesa. Enfim, no seio do precariado reside a contradição radical da forma-mercadoria entre valor de troca e valor de uso (2013b, p. 2)

É considerando esta contraditoriedade constitutiva que Guy Standing (2011; 2013) caracteriza o precariado como a nova classe perigosa, alertando que a sua emergência e expansão pode levar a uma política de inferno ou a uma política de paraíso, a depender dos rumos de sua formação como uma classe-para-si.

Em um processo de aproximações sucessivas na problematização em curso, é importante delinear, como via investigativa, que este precariado, constituído por trabalhadores assalariados jovensadultos, no contexto da mistificação ideológica que sustenta a civilização do capital, encarna a invisibilidade social de sua natureza de classe. A 
rigor, a precariedade estrutural do trabalho determina que estes trabalhadores, em suas trajetórias de vida, desenvolvam identidades fragmentadas, pulverizadas com a implosão dos laços de solidariedade. É a precarização das identidades individuais e coletivas, como sinaliza Druck (2009). Nestes processos identitários precários, não conseguem constituir uma consciência de classe. Avalia Giovanni Alves (2012a, p. 2)

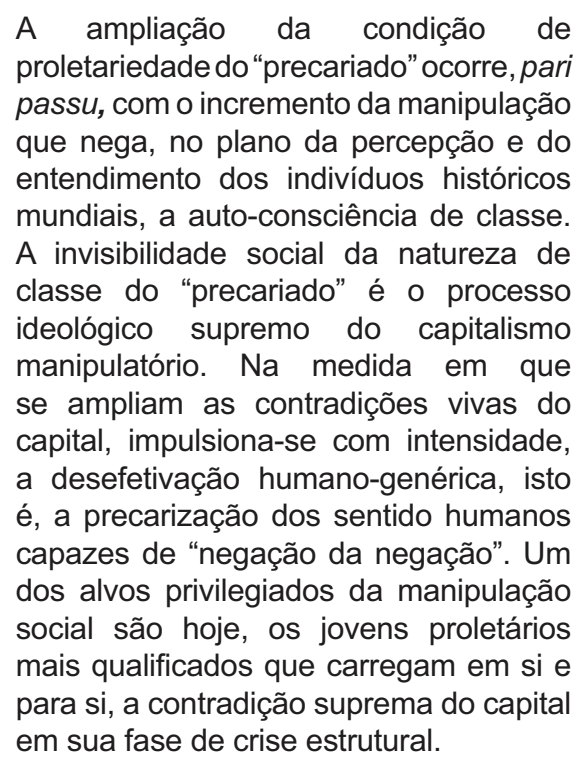

É inconteste que, nos movimentos da História, nos circuitos da crise do capital, no início da segunda década do século XXI, multidões desses jovens precários, nas cidades europeias, norteamericanas, latino-americanas e, particularmente, nas cidades brasileiras, no limite de sua angústia, de sua frustração e indignação, tomam consciência de sua situação de vulnerabilidade e insegurança econômica e social, assumindo novas formas do conceber e do fazer político, a articular a potencialidade de universalização do ciberespaço e a possibilidade histórica de coletivização da ágora, na ressignificação das praças como territórios políticos. Coloca-se em questão o que se pode esperar de sua mobilização e singulares formas de organização política, materializadas nas grandes manifestações em praças e ruas que surpreenderam o mundo, marcando o ano de 2011, na Europa, nos Estados Unidos e em países da América Latina, como ano rebelde, com ampla divulgação midiática, espetacularizando o regresso da política, a (re) constituir, em tempos contemporâneos do século XXI, praças e ruas em espaços públicos. No Brasil, a surpresa histórica das rebeliões juvenis marca o ano de 2013, como o nosso ano rebelde, transformando a onda massiva de protestos e a intensa repressão policial em espetáculo midiático inesperado que irrompe em meio ao espetáculo oficial da Copa das Confederações!

E passada a fase espetacular das ondas massivas de protestos e revoltas, as mobilizações do precariado continuam e consolidam-se, sem o impacto da surpresa histórica, a questionar o modo privatizante de viver, sem a cobertura da chamada grande mídia e restrita ao espaço das mídias alternativas, impondo uma questão-chave no decifrar do enigma: qual a força emancipatória das lutas deste precariado, a questionar a ordem do sistema do capital mundializado e as instituições democráticas, sedimentadas nos circuitos históricos do capitalismo? Quais as potencialidades e limites da sua insurgência e indignação como uma multidão global de destituídos e despojados a constituir, hoje, a multidão do precariado? É esse um campo de polêmicas em aberto, a configurar uma agenda de debates e investigações!

Guy Standing (2011; 2013) sustenta a exigência histórica do precariado ser considerado como classe emergente, em suas inseguranças e interesses, o que tem impactos e implicações no âmbito das políticas públicas. E defende a exigência da universalização dos Programas de Renda Básica, no sentido da redistribuição da riqueza monetária a questionar a lógica mercantil do capital, constituindo a alternativa para enfrentar o capitalismo contemporâneo e atender o precariado em sua necessidade vital de segurança.

Giovanni Alves (2012a; 2013a) sinaliza que o precariado, a conferir visibilidade, nos primórdios do século XXI, à grande massa da humanidade destituída de propriedade - proclamada por Marx e Engels - estaria a encarnar a oportunidade radical de afirmação de indivíduos históricomundiais empiricamente universais, cabendo, nesta perspectiva, considerar o papel da Internet, com seus blogs alternativos e redes sociais, na construção das individualidades histórico-mundiais.

Em verdade, o precariado, como enigma contemporâneo, constitui uma interpelação investigativa, a colocar o desafio de fazê-lo um concreto pensado, no pleno exercício da imaginação dialética. Impõe-se, hoje, mais do que nunca, como exigência histórica, a consciência crítica, capaz de apreender, com radicalidade, processos sociais que surgem nesta nova temporalidade da civilização do capital em crise. É a construção do pensamento crítico, no processo permanente de ampliações conceituais, como fardo histórico do tempo presente, buscando criar condições sociometabólicas para a negação da negação.

\section{REFERÊNCIAS}

ALVES, Giovanni. O enigma do precariado e a nova temporalidade histórico do capital - partes 1, 2 e 3. [S. I.: s. n.], 2012a. Disponível em: <http://boitempoeditorial.wordpress.com/2012/ 14/o-enigma-do-precariado>. Acesso em: 22 jul. 2012. 
BENJAMIN, C. Atualidade de Marx. Revista Espaço Acadêmico, Maringa, Paraná, n. 42, 2004.

BRAGA, Ruy. A política do proletariado - do populismo à hegemonia lulista. São Paulo: Boitempo, 2012.

CARVAlHO, Alba Maria Pinho de. Políticas públicas e o dilema de enfrentamento das desigualdades: um olhar crítico sobre a América Latina no século XXI. In: SOUSA, Fernando José Pires de (Org.). Poder e políticas públicas na América Latina. Fortaleza: Edições UFC - RUPAL, 2010.

; CASTRO, Alba Tereza Barroso de. Crise do capital e dilemas do desenvolvimento: padrão brasileiro de inserção no capitalismo mundializado. Revista em Pauta: Revista da Faculdade de Serviço Social, Rio de Janeiro, n. 31, v. 11, 2013.

CAZES, Leonardo. Precariado: o trabalho em crise. Jornal O Globo, [S. I.], 2013. Disponivel em: <http:// oglobo.globo.com/blogs/prosa/posts/2013/10/19/ precariado-trabalho-em-crise-512502>. Acesso em: 19 out. 2013.

CHESNAIS, François et al. A nova economia: uma conjuntura própria à potencia econômica estadunidense. São Paulo: Xamã, 2003.

COUTINHO, Carlos Nelson. A dualidade de poderes: Estado e Revolução no pensamento marxista. In: _. Marxismo e Política a dualidade de poderes e outros ensaios. São Paulo: Cortez Editora, 1994.

DRUCK, Graça. Principais indicadores da precarização social no Brasil. In: CONGRESSO BRASILEIRO DE SOCIOLOGIA, 2009, Rio de Janeiro. Anais... Rio de Janeiro: Sociedade Brasileira de Sociologia, jul. 2009. Disponível em: $<w w w . c o l o q u i o-s s o . b l o g s p o t . c o m / 2010 / 04 /$ coloquio. html>. Acesso em: 5 dez. 2011.

HARVEY, David. O enigma do capital e as crises do capitalismo. São Paulo: Boitempo, 2011.

MARX, Karl. Grundrisse: manuscritos econômicos de 1857-1858: esboços da crítica da economia política. São Paulo: Boitempo; Rio de Janeiro: Ed. UFRJ, 2011.

MÉSZÁROS, István. A crise estrutural do capital. São Paulo: Boitempo, 2009.

STANDING, Guy, The precariat - The New Dangerous class. New York: Bloomsbury Academic 2011. Disponível em http://www.outraspalavras:net/ files/2012/06/120628-precariado.livro.pg. Acesso em: 15 ago. 2012. enigma contemporâneo

ZIZEK, Slavoj. Vivendo no fim dos tempos. São Paulo. Boitempo, 2012.

DEMOCRACIA RADICAL E PODER NA TEIA GLOBAL DOS INDIGNADOS: horizontes de uma nova cultura política no século XXI

AGAMBEN, G. O que é o contemporâneo?: e outros ensaios. Argos, 2009.

ALVAREZ, S.; DAGNINO, E.; ESCOBAR, A. (Orgs.). Cultura e política nos movimentos sociais latinoamericanos: novas leituras. Belo Horizonte: Ed. UFMG, 2000.

ALVES, G. O enigma do precariado e a nova temporalidade histórica do capital. São Paulo, 13 jul. 2012. Disponível em: <http://boitempoeditorial. wor dpress.com/category/ colunas/giovanni-alves/>. Acesso em: 25 set. 2012.

BEY, H. Zona autônoma temporária. [S.I.] Autonomedia, 1991.

CHESNAIS, Fs. A mundialização do capital. São Paulo: Xamã, 1996.

DOMINGUES, J. M. Aproximações à América Latina: desafios contemporâneos. Rio de Janeiro: Record, 2007.

FOUCAULT, M. Microfísica do poder. Organização e tradução de Roberto Machado. 4. ed. Rio de Janeiro: Graal, 1984.

O sujeito e o Poder (1983). In: RABINOW, P.; DREYFUS, H. Michel Foucault: uma trajetória filosófica para além do estruturalismo e da hermenêutica. Rio de Janeiro: Forense Universitária, 1995.

HARDT, M.; NEGRI, A. Multidão: guerra e democracia na era do império. Rio de Janeiro: Record, 2005

Império. Tradução de Berilo Vargas. ed. 2. Rio de Janeiro: Record, 2001.

HARVEY, D. O enigma do capital: e as crises do capitalismo. Tradução de João Alexandre Pechanski. São Paulo: Boitempo, 2011.

et al. Occupy: movimentos de protestos que tomam as ruas. Tradução João Alexandre Peschanski. et al. São Paulo: Boitempo, 2012.

HUIZINGA, J. Homo Ludens. 4. ed. São Paulo: Perspectiva, 2000.

LIPOVETSKY, G. A felicidade paradoxal: ensaio sobre uma sociedade de hiperconsumo. São Paulo: Companhia das Letras, 2007. 
MARX, K. Grundrisse: manuscritos econômicos de 1857-1858: esboços da crítica da economia política. Supervisão editorial Mario Duayer, Tradução Mario Duayer, Nélio Schneider, Colaboração de Alice Helga Werner e Rudiger Hoffman. 1. ed. São Paulo: Boitempo; Rio de Janeiro: Ed. UFRJ, 2011.

MORIN, E. O século XXI começou em Seattle. Le Monde, Paris, dez. 1999.

NEGRI, A. El movimiento de los movimientos. In: CICLO DE SEMINARIOS INTERNACIONALES: pensado el mundo desde Bolivia, 1., 2010.

\section{REVISTA CULT. O que pensam os jovens que ocupam as ruas. São Paulo: Edição 182, 2013. Disponível em:<http://revistacult .uol.com.br/home/2013/08/o-que-pensam-os-jovens- que-ocupam-as-ruas/>. Acesso em: 18 ago. 2013.}

SOUSA SANTOS, B de. A gramática do tempo: para uma nova cultura política. 2 ed. São Paulo: Cortez Editora, 2008. v. 4.

ZIZEK, S. In: HARVEY, D. et al. Occupy: movimentos de protestos que tomam as ruas. Tradução João Alexandre Peschanski. et al. São Paulo: Boitempo, 2012.

\section{NOTAS}

1 Considero que, na contemporaneidade, o capitalismo mundializado, na imbricação dialética do modo de produção e do modo de vida, constitui um regime civilizacional, a estender a lógica do capital aos diferentes domínios da vida social, mesmo àqueles que, outrora, dificilmente seriam concebidos como capitalistas: religião, relações afetivas, concepção do tempo livre, avaliação do mérito científico e avaliação moral dos comportamentos.

2 Uma discussão sobre a natureza da crise estrutural do capital no século XXI, seus elementos determinativos e sua dinâmica interna nos circuitos da acumulação rentista encontra-se consubstanciada no texto da Mesa Temática Coordenada Reconfigurações do Estado e das Políticas Públicas no contexto da crise estrutural do capital, de autoria de Alba Carvalho, Alcides Gussi e Carlos Américo Moreira, apresentada na $V$ Jornada Internacional de Políticas Públicas, no período de 23 a 26 de agosto de 2011.

3 István Mészáros $(2009 ; 2013)$ sustenta que esta crise estrutural do sistema como um todo - que é o que define o atual período histórico - está vinculada ao final dos anos 1960, aprofundando-se desde então, a exigir mudanças estruturais para uma solução duradoura possível.

4 Nesta perspectiva, Giovanni Alves (2013), em seu livro de 2013 de ensaios críticos, intitulado Dimensões da Precarização do Trabalho - Ensaios de Sociologia Política, apresenta um sistema categorial novo para tratar do novo (e precário) mundo do trabalho no século $X X I$ : maquinofatura, precarização do homem-que-trabalha, nova precariedade salarial, experiências expectantes; crise do trabalho vivo como redução do trabalho vivo à força de trabalho em suas manifestações contingentes; crise da vida pessoal, crise de sociabilidade e crise de autorreferência pessoal; dessubjetivação de classe, captura da subjetividade do homem-que-trabalha, condição de proletariedade, trabalho ideológico e a redefinição dos conceitos de crise estrutural de valorização e conceito de precariado. Alerta Alves (2013, p. 10) que esses novos conceitos são "[...] elementos de provocação heurística categorizações propositadamente precárias no sentido de que exigem lapidações críticas necessárias e recorrentes".

5 A Revolução Técnico-científico-informacional emerge e constitui-se na segunda metade do século XX, principalmente a partir da década de 1970, fundada em descobertas científicas, encarnadas emextraordinárias revoluções tecnológicas: informática, cibernética, robótica, telecomunicação, química, uso de novos materiais, biotecnologia, engenharia genética, dentre muitas outras. Assim, esta III Revolução Industrial viabiliza o desenvolvimento de uma nova base técnica informacional para o capitalismo global, demarcando uma terceira modernidade do capital, a exigir um novo metabolismo social, capaz de promover um novo patamar de acumulação capitalista.

6 Giovanni Alves (2013, p. 23), ao tomar, como referência, a demarcação de Karl Marx, no livro I de O Capital, das duas formas históricas de produção social do capital - manufatura e grande indústria - sugere, como terceira forma social da produção do capital, o que denomina de maquinofatura. E, esclarece que, na análise marxiana, o ponto de partida do revolucionamento do modo de produção capitalista na manufatura é a força de trabalho e já na grande indústria é o meio de trabalho, ou seja, a técnica. Assim, sustenta Alves (2013, p. 23) que, sob as condições do que chama "terceira modernidade do capital, o ponto de partida da maquinofatura [...] não é o revolucionamento da força de trabalho (como na manufatura), nem o revolucionamento da técnica (como na grande indústria), mas sim o revolucionamento do homem-e-da-técnica, ou o revolucionamento da própria relação homem-técnica."

7 Uma chave analítica decisiva é ter clareza da distinção entre a categoria condição de proletariedade e o conceito de classe social. Esclarece Giovanni Alves que "[...] classe" diz respeito ao sujeito histórico, capaz de ação social e política, em si e para si (e para além de si), capaz de 'negação da negação' da alienação e suas múltiplas determinações; a 'condição de proletariedade' designa a condição existencial objetiva historicamente constituída pelo modo de produção do capital e no interior da qual pode (ou não) se constituir o sujeito histórico de classe". Assim, estar imerso na condição existencial do proletariado não significa necessariamente pertencer à classe social do proletariado. Significa, sim, vivenciar a condição de alienação e estranhamento social da ordem do capital, no sentido do trabalho estranhado e da vida social estranhada, subjacente à produção do capital. 
Em uma síntese conceitual, afirma Alves (2013a, p. 196) que a "[...] multidão' designa o contingente de individualidades pessoais imersas na condição de proletariedade. A multidão expressa o ser-aí (dasein) de homens e mulheres reduzidos objetivamente à condição de alienação/estranhamento social".

8 Guy Standing (2013, p. 26, 27), ao empreender o esforço de definir o precariado faz incursões sobre o uso do termo no sentido de demarcando alguns elementos-chave: "[...] o termo descritivo 'precariado" foi usado pela primeira vez pelos sociólogos franceses nos anos 1980, para descrever os trabalhadores temporários ou sazonais [...] o significado do termo tem variado na medida em que entra no debate popular. Na Itália, o termo 'precariato' tem sido empregado para significar mais do que apenas pessoas cumprindo tarefas casuais e com baixas rendas, indicando a existência precária com um estado de vida normal [...] Na Alemanha, o termo tem sido usado para descrever não apenas trabalhadores temporários, mas também desempregados que não têm esperança de integração social [...] No Japão, o termo tem sido usado como sinônimo de "trabalhador pobre" embora tenha evoluído como um termo distintivo na medida em que passa a ser associado com o movimento japonês do Dia do Trabalho e os chamados "sindicatos freeter", formados por jovens ativistas que exigem melhores condições de trabalho e de vida [...] O Japão tem produzido um grupo de jovens trabalhadores conhecidos como "freeters" um nome que combina peculiarmente "free" (livre) e Arbeiter, palavra alemã para trabalhador - que tem sido forçado a um estilo de emprego casual." Cabe destacar que, no delineamento da polêmica conceitual, incido o foco nas construções analíticas que Guy Standing, Giovanni Alves e Ruy Braga desenvolvem em suas produções, consciente de que este é um debate em aberto, a exigir esforço sistemático de investigação, na vinculação dialética História e Teoria.

9 Guy Standing é Professor de Estudos de Desenvolvimento na Escola de Estudos Orientais e Africano (SOAS). Junto com o senador Eduardo Suplicy e o professor Claus Offe, é co-presidente da BIEN (Rede Planetária pela Renda Básica/ Basic Income Earth Network).

10 Giovanni Alves é professor da UNESP-Marilia, livredocente em teoria sociológica, pesquisador do CNPq, desenvolvendo projeto de pesquisa intitulado $A$ derrelição de Ícaro - Sonhos, expectativas e aspirações de jovens empregados do novo (e precário) mundo do trabalho no Brasil (2003-2013). É um dos líderes do GPEG - Grupo de Pesquisa Estudos da Globalização, e da RET - Rede de Estudos do Trabalho.

11 Rui Gomes Braga Neto é sociólogo brasileiro, especialista em sociologia do trabalho. Atualmente, trabalha como professor do Departamento de Sociologia da Faculdade de Filosofia, Letras e Ciências Humanas da Universidade de São Paulo (USP) onde coordenou o Centro de Estudos dos Direitos da Cidadania (Cenedic). É editor da revista Outubro (Revista do Instituto de Estudos Socialistas).
12 Trata-se de uma entrevista, por e-mail, concedida por Guy Standing a Leonardo Cazes e que constitui referência na matéria de Cazes, publicada em caderno do Jornal O Globo de 19 de outubro de 2013, conforme consta nas Referências.

13 Esta aproximação categorial em que Giovanni Alves trabalha de per si cada uma das três variáveis constituintes do precariado, em sua construção analítica, foi apresentada em texto de um e-mail em que o pesquisador responde a questões levantadas pelo mestrando de Sociologia da Universidade Federal do Ceará (UFC) Francisco Raphael Cruz Maurício, a partir de amplas discussões desenvolvidas no interior do grupo de um Curso de Leitura que orientei, no primeiro semestre de 2013 , no Programa de Sociologia da UFC. Considerando a qualidade da síntese conceitual então sistematizada por Alves, como pauta de reflexões, decidi transcrever trechos deste significativo material de investigação.

14 Para uma análise do Brasil Contemporâneo no século $X X I$, constituído em meio às políticas de ajuste e ao neodesenvolvimentismo, ver produções circunscritas nas Referências: Brasil en el siglo XXI: inserción en el capitalismo financeirizado y neointervencionismo del Estado de Alba Carvalho; Posição do Brasil no contexto latinoamericano: dependência nas tramas da autonomia e do subdesenvolvimento" de Alba Carvalho; Crise do capital e dilemas do desenvolvimento: padrão brasileiro de inserção no capitalismo mundializado de Alba Carvalho e Alba Castro. A partir desta análise do modelo brasileiro, impõe-se a exigência de avançar nas configurações da morfologia social do trabalho no Brasil no século $\mathrm{XXI}$, investigando as expressões do precariado na cena brasileira contemporânea.

15 Uma ampla e consistente configuração analítica da nova morfologia do trabalho no Brasil na década de 2000, nos marcos da nova precariedade salarial é desenvolvida pelo pesquisador Giovanni Alves em Oficina no Centro de Estudos Sociais (CES) da Universidade de Coimbra, em 2012. Este trabalho - devidamente explicitado nas referências circunscreve a temporalidade histórica no interior da qual emergiu o novo e precário mundo do trabalho no Brasil, nos anos 2000 , analisando a nova morfologia social do trabalho flexível e seus impactos no sociometabolismo laboral.

\section{Alba Maria Pinho de Carvalho}

Assistente Social

Doutora em Sociologia pela Universidade Federal do Ceará (UFC)

Professora do Departamento de Ciências Sociais da Universidade Federal do Ceará (UFC)

E-mail: albapcarvalho@gmail.com

\section{Universidade Federal do Ceará - UFC}

Avenida da Universidade, 2853 - Benfica, Fortaleza CE. CEP: $60020-181$ 